\section{P-241 LEADING THE WAY - CREATING A DIVERSE TRUSTEE BOARD}

Robin Webb. Isabel Hospice, Welwyn Garden City, UK

\subsection{6/bmjspcare-2018-hospiceabs.266}

Background $62 \%$ of top charities have all-white boards, according to Inclusive Boards (2018), and the report 'Taken on trust: the awareness and effectiveness of charity trustees in England and Wales' (2017), found 71\% of trustees were approached to join either directly by the chair or fellow board members. Insanity is often defined as: 'Doing the same thing over and over again and expecting different results'.

We need to build diverse boards that bring in a wide range of talent, skills and experiences. Therefore, we must be intentional in our recruitment for these key roles. This will ensure we have the best people to lead our organisations in these interesting times.

Aims To recruit a diverse mix of new trustees to our board with a variety of skills and experiences as part of our plan to build and develop a high performing Board.

Method

- June to August 2017 - Trustees reviewed skills by selfassessment.

- In context of our strategic development plans gaps in skills identified.

- September to October 2017 - extensive advertising; national newspaper (Guardian), non-exec recruitment websites, local media, case studies in publications

- October 2017 - $2 \times$ open evenings held for people interested in exploring the role to meet existing trustees and Exec. directors

- November 2017 - applications shortlisted, formal interviews held

- December 2017 - new trustees appointed.

Results 22 people attended two open evenings; 17 applications received; 14 interviewed; five appointed. Skills and experience recruited included two lawyers, investment and financial expertise, medical management and local government. Four women, one man. Three from non white English backgrounds. Four aged 42-51 and one in 60s.

It is too early to evaluate the impact of this greater diversity on the effectiveness of the Board; a review is planned for 2019. Conclusion Our past experience and published research confirms that trustees recruiting their friends results in similar people from similar background joining charity Boards. If charities want to build greater diversity on their boards, drawing in a wider range of skills, experience and backgrounds then being intentional about the approaches they take can deliver these ambitions.

\section{P-242 TRANSFORMING A TRADITIONAL HOSPICE INTO A CONTEMPORARY PALLIATIVE CARE PROVIDER}

Claire Marshall. Compton Care, Wolverhampton, UK

\subsection{6/bmjspcare-2018-hospiceabs.267}

Background With escalating demands of the healthcare and social sector, increased regulation and negative press coverage about the role of charities, the need for bold purpose and direction for healthcare charities is paramount for future survival. This paper charts the rapid root and branch transformation of a traditional local hospice into a contemporary palliative care provider: the positive impact of service user input, the challenge of changing an entrenched culture and the dichotomy of leading a local charity against the commercial realities of the sector.

Aim With a significant time imperative the aim was to effect full scale and fast but effective transformation of the hospice in providing it with a new focus, ambition and strategy in order to navigate its way through the challenges of the healthcare economy and future proof its vision and strategy.

Methods and results A significant consultation and perception study was undertaken to involve every form of stakeholder to understand the status of the organisation and how it was viewed by its community. The process and feedback were used to engage the organisation in co-designing its new vision, mission, values, brand and three year strategy. The initial transformation has been completed and was successful, the strategy in its first year of implementation. The cultural change has been fundamental despite being the most challenging aspect and most difficult to measure in the long term.

Conclusions and innovation The listening process, sharing challenging feedback from important stakeholders and authentic and disruptive leadership were the backbone of inspiring and effecting rapid change but there are numerous points of learning or improvement for other organisations considering the same path or elements of it. The impact of the volunteer workforce in a charity setting and the importance of leading the process, not as a project but as a cultural transformation.

\section{P-243 END OF LIFE CARE EDUCATION WITHIN THE NURSING AND RESIDENTIAL HOME SETTING}

Imelda Hodgkinson, Caroline Vince, Christine Aylott, Jacquie Pamphilon, Jennifer Chandler, Karen Chumbley. St Helena Hospice, Colchester, UK

\subsection{6/bmispcare-2018-hospiceabs.268}

Background The development and facilitation of end of life education arose in response to the specific learning needs identified by local nursing and residential homes. This initiative originated as a result of staff supervision sessions, Care Quality Commission recommendations and a desire to improve the care and support offered to residents and their families.

Aim The overriding purpose in providing this education was to cascade knowledge and best practice from the specialist palliative care community to the homes. This dynamic approach lends itself to improving the quality of person-centred care provision and staff confidence with emphasis on collaboration and a shared focus, to enhance end of life care.

Method The specific learning requirements of the staff regarding end of life care were identified. The curriculum was then developed and delivered focusing entirely on the agenda of the learners. This included some similar themes such as recognition of the dying process, priorities and preferences at the end of life, communication and symptom management issues. The educational sessions were delivered through some elements of didactic presentation, interactive group discussion, role play, simulation and case studies.

Results In total education sessions have been delivered to six homes, with a total of 69 staff participating with the overall satisfaction rate at $100 \%$. As a consequence of the education delivered, the feedback has led to further learning needs being identified. 